\title{
Ferulização de dentes pelo uso de prótese adesiva
}

\author{
Ézio Teseo Mainieri* \\ Luiz Fernando Walber** \\ Roberto Sperb Seadi***
}

RESUMO

Este trabalho consiste em uma análise sobre splintagem procurando enfocar função, vantagens, implicaçōes e o desenvolvimento de uma técnica de fixação através de próteses e cimentos adesivos.

\section{SUMMARY}

This paper approches the splint trying to focuse function, advantages, implications and the development of a fixation technique by means of prosthesis and bond-resin.

\section{UNITERMOS}

\author{
Ferulização, Conteção, Splintagem.
}

\section{Introdução}

Splintagem é a união mecânica de dentes com o objetivo de eliminar o trauma de oclusão, o aumento de mobilidade e a manutençăo da estética. Isto porque, vários dentes unirradiculares unidos, funcionam como uma unidade multirradicular, diminuindo a força oclusal e aumentando a resistência periodontal.

Dentes submetidos a esforços além de seu limite fisiológico, necessitam de uma estabilização que possibilite um posicionamento adequado e uma cicatrizaçăo inicial. Traumas e doença periodontal são situaçōes mais frequentes de indicação exigindo, normalmente, um splint de urgência, de tempo médio ou até mesmo permanente. Selispki constatou que dentes com padrōes de mobilidade existentes após a terapia inicial são essencialmente os mesmos daqueles que existia após a cicatrização total da cirurgia periodontal. Ele demonstrou que a maior redução na mobilidade, ocorre como resultado da terapia inicial. Portanto, a necessidade de ferulizar deve ser determinada após a terapia inicial e antes da intervençăo cirúrgica.
As técnicas usadas na confeção de splints fixos são similares às de pontes fixas, variando apenas em função do tempo de uso clínico requisitado pelo caso e das condições físicas e financeiras do paciente.

Embora a splintagem permita a manutenção dos dentes com $a$ inserção severamente comprometida, sua eficácia depende dos seguites fatores:

- Número, alinhamento e distribuição dos dentes

- Grau de mobilidade dos dentes

- Grau de rigidez da splintagem

- Dentição oposta

A splintagem como procedimento biológico atua direta, uniforme e inteiramente sobre o ligamento periodontal. Uma vez que os procedimentos protéticos, envolvendo a splintagem, diminuem a mobilidade dos dentes, pela distribuição de forças, com o suporte promovido pelos ligamentos periodontais, dos demais pilares. Somente forças resultantes axiais transmitidas ao periodonto produzem estimulação fisiológica do aparato fibroso. As fibras oblíquas são submetidas a estimulaçăo e reorientaçăo, quanto as forças axiais, enquanto que as forças laterais são absorvidas pelas fibras coronárias e apicais. Apesar de que as fibras coronárias e apicais năo resistem e não dissipam adequadamente os esforços laterais, mesmo após a sua reorientação, ainda mais com presença de perda de suporte óssea e de parte do ligamento periodontal.

O procedimento de splintagem transforma um simples dente, isolado, com mobilidade em um novo dente multirradicular pela sua associação com outros dentes com menor mobilidade. A splintagem envolvendo dentes unirradiculares orienta o centro de rotação do conjunto de dentes splintados entre si. $\mathrm{Na}$ direção as superfícies radiculares, incorporando ao splint uma função de unidade dental multirradicular com aumento da área total radicular, favorecendo a relação de suporte coroaraiz.

Funçāo - A funçăo de um splint refere-se a distribuiçăo e direcionamento de forças funcionais e para-

\footnotetext{
* Professor Adjunto

** Professor Auxiliar

*** Cirurgiāo-Dentista
} 
funcionais, a fim de trazê-las a um limite de tolerância aos tecidos de suporte, e para eliminar qualquer mobilidade presente.

As funçōes básicas de um splint podem ser consideradas como:

1. Estabilização: aumento da área radicular de resistência

2. Reorientação de stress e forças Efeitos Secundários:

a) na força e função

b) modificação dos padrões oclusais

c) ajuste das relações maxilomandibulares

d) melhora a eficiência mastigatória

Definitivamente os aparelhos splintados promovem distribuição do impacto proveniente das forças mastigatórias.

As vantagens que a splintagem nos oferecem săo:

1. Redireção das forças

2. Redistribuição das forças

3. Prevenção da migraçăo

4. Prevenção da supra-erupção

5. Estabilização dos dentes inclinados

6. Eliminação da impacção alimentar

7. Estabilização e fortalecimento dos suportes

Splintagens unilaterais, bilaterais ou estabilização cruzada são algumas das alternativas a serem usadas. Quando o envolvimento entre arcos ocorre, a máxima estabilização é obtida.

A splintagem deve ser um ato bem pensado, pelas suas implicaçōes. A mobilidade por si só não é indicação de splintagem. Em algumas situações, basta que se faça um ajuste oclusal para se obter uma melhora considerável da situação. Splintar implica em:

1. Dificuldade de higienização

2. Aumento de custos

3. Dificuldade de exame para controle

4. Desgaste de tecido dentário

No uso pleno dos princípios de estabilização pela splintagem associamos o uso recente de próteses e cimentos adesivos, com a vantagem precípua da conservação do tecido dentário.

A splintagem através de prótese adesiva tem se tornado o tipo mais comum de splint permanente. Sua principal característica positiva é não exigir muita ou quase nenhuma preparação dos dentes. Possibilitando, ainda, estética, menor tempo de trabalho clínico, custo reduzido, reversibilidade e não envolvimento pulpar.

\section{Princípios da preparação}

Utilizamos os mesmos princípios para prótese adesiva, a qual combina alguns elementos das modificaçōes dentárias produzidas na prática da prótese fixa e prótese removível.

Definição de um plano de inserção único e definitivo, inciso-gengival. Fig. 1. cionando um mínimo de $0,3 \mathrm{~mm}$ de espessura de metal, sem causar sobrecontorno.

Apoios oclusais definidos promovendo adequado assentamento e estabilidade oclusal à prótese.

Margens bem definidas, supra gengivais, satisfazendo requisitos estéticos e periodontais.

Modagem - com elastômero.

Modelos em gesso pedra, montados em articulador.

Fase Laboratorial

Enceramento

Fundição

Prova da Inserção

Primeira Prova - A estrutura metálica pode ser testada com a porcelana

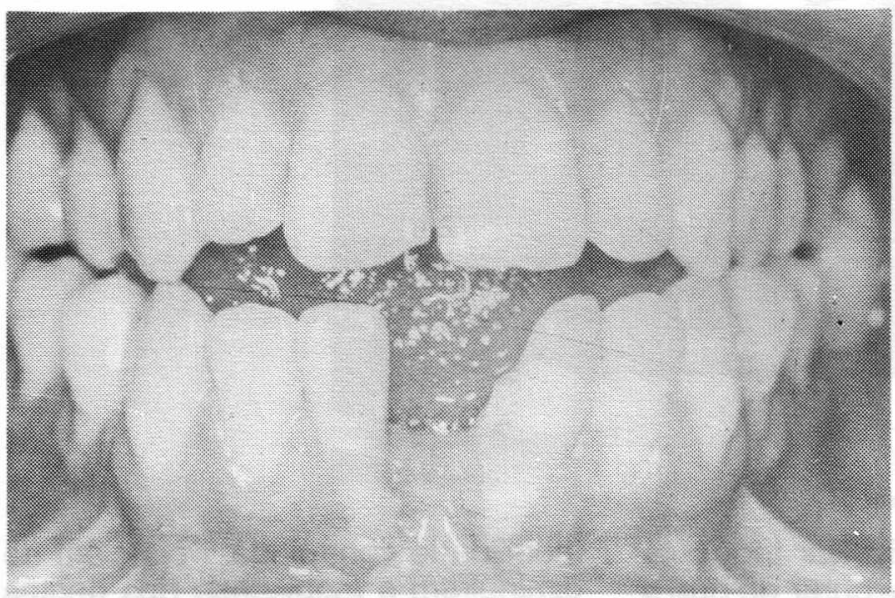

FIGURA 1: Caso clínico mostrando um plano de inserção único

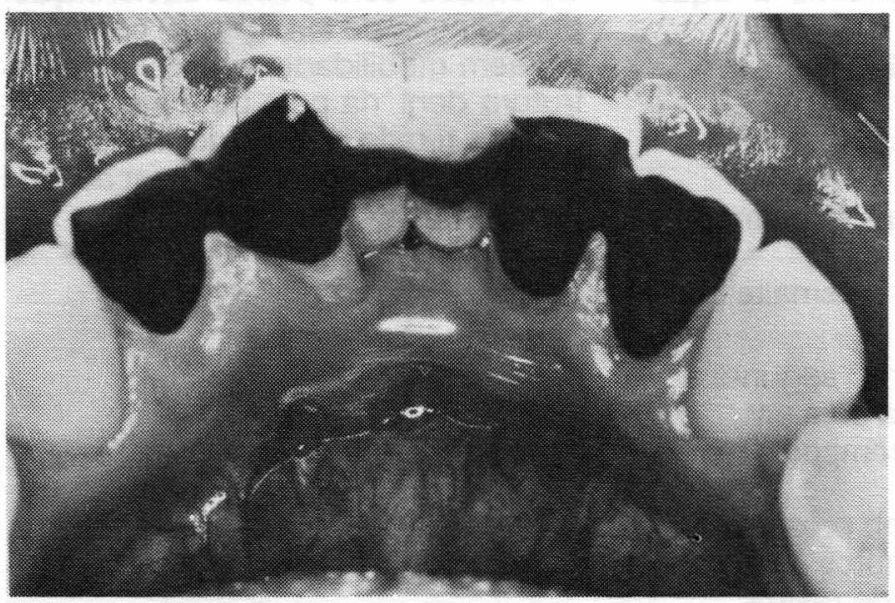

FIGURA 2: Prova da estrutura metálica com porcelana

Forma de retençăo nos pilares para possibilitar um eixo único de inserçăo e remoção.

Substancial abraçamento, igual ou aproximadamente 180 graus, através do preparo para resistir ao deslocamento da peça dentária.

Suficiente reduçăo oclusal propor- aplicada em sua primeira queima (Figs. 2 e 3), possibilitando observar:

- o assentamento da prótese

- a resistência ao deslocamento lingual

- a adaptação marginal

- possibilidade de excurções mandibulares. 


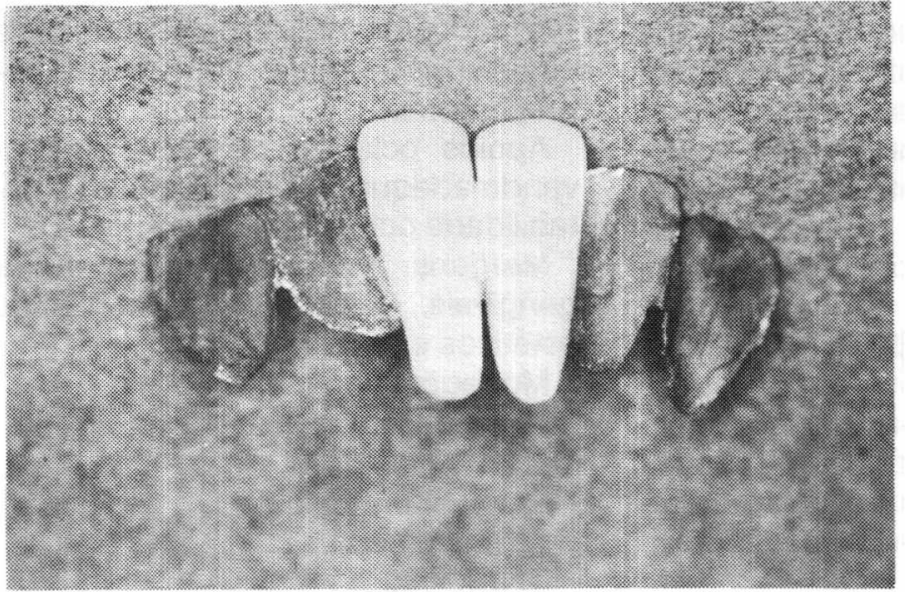

FIGURA 3: Vista interna da prótese adesiva

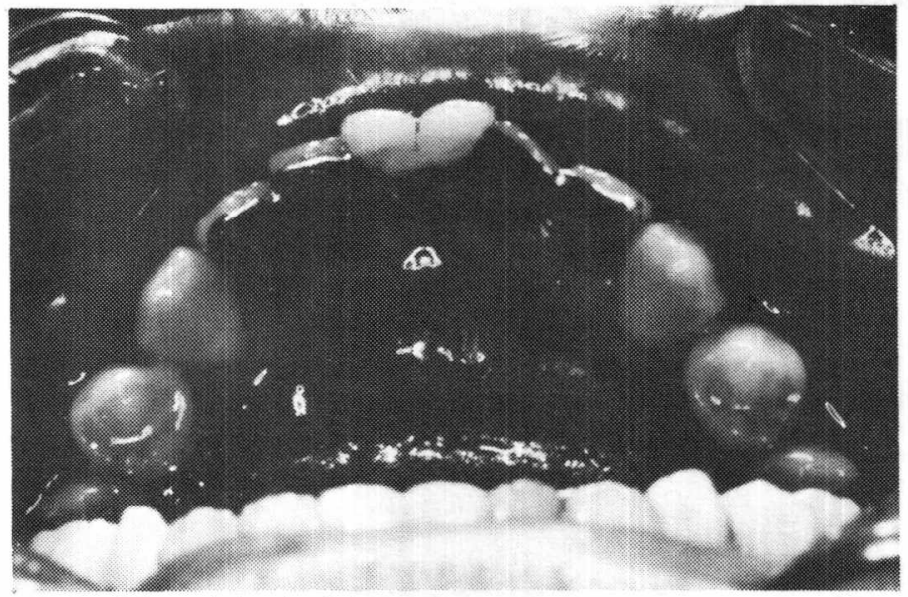

FIGURA 4: Prótese adesiva cimentada

Segunda Prova - Revisar todos os ítens anteriores e assegurar de que a prótese está esteticamente adequada.

\section{Condicionamento do Metal}

Colagem da Peça

- o isolamento absoluto é obrigatório

- polimento dos dentes que serão atacados

- ataque ácido sobre o esmalte por 30 a 60 segundos

- lavar com água por 30 segundos

- cimentação da peça com um cimento de resina composta BIS-GMA

- manter a prótese sob pressão constante por 7 minutos

- remover o excesso de resina

- instruir o paciente para evitar pressão por 24 horas

- nova consulta para revisar a colagem e a oclusão (Figs. 4 e 5). Acreditamos que o uso de férulas fixas em metalo cerâmica, associada as técnicas de prótese adesiva, promovem dupla vantagem em tratamentos que envolvam dentes com

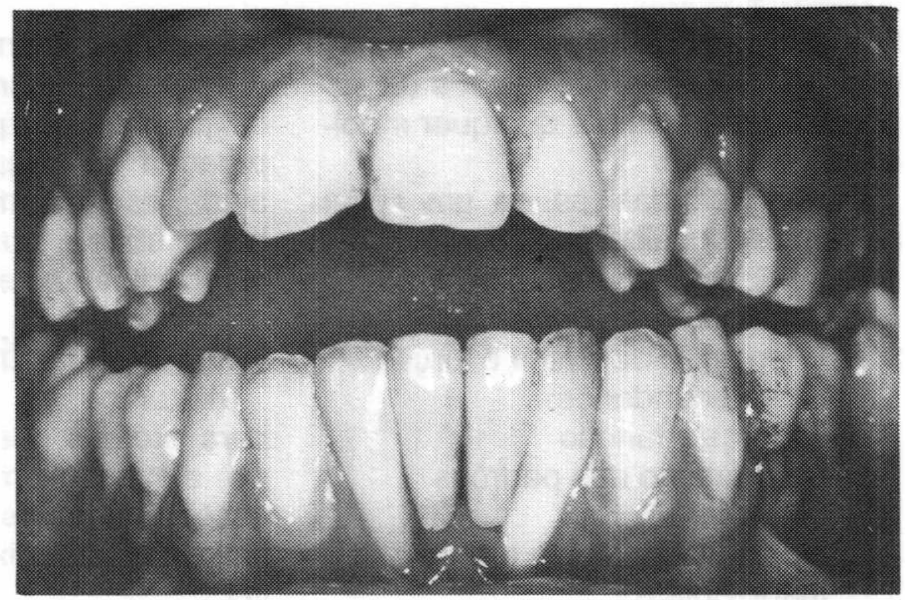

FIGURA 5: Prótese adesiva cimentada - vista estética mobilidade controlada. Pois além de diminuirem a mobilidade dos dentes envolvidos com pouca sustentação, pela relação de ferulização, com dentes sem mobilidade, preservam a estrutura dent 'ria pela pouca quantidade de tecido envolvido na preparação e pela ação de retenção dos novos cimentos adesivos.
REFERÊNCIAS BIBLIOGRÁFICAS

01. BUONOCORE, M.G.: A simple method for increasing adhesion of acrylic resin filling materials to enamel. J. Dent. Res. Washington, v.34, p.849-853, 1955.

02. BUONOCORE, M.G.: Retrospections on bonding. Dent. Clin. North Am. Philadelphia, v.25, n.2, p.241-255, 1981

03. CARLSON, B.R. YONTCHEV, E. CARLSSON, G.E.: Extensive fixed partial dentures on mandibular canine teeth: A 5year recall study. Int. J. Prosth. v.2, n.3, p.265-271, may/june, 1989.

04. DAWSON, P.E.: Avaliaçāo, diagnóstico e tratamento dos problemas oclusais. São Paulo: Artes Médicas, 1980, 405p.

05. KORNFELD, M.: Rehabilitation bucal - procedimentos clinicos y de laboratorio. Argentina: Mundi, 1972, 2v.

06. LINDHE, J. et al.: Functional analysis of fixed bridges on abutment teeth with reduced periodontal support. J. Oral Rehabili. Oxford, v.2, p.105-116, 1975.

07. MALONE, W.F.P.; KOfH, D.L.: Teoria e prática de prótese fixa de Tylman. 8ed. Artes Médicas, 1990. 503p.

08. NYMAN, S.; ERICSON, I.: The capacity of reduced periodontal tissue to support fixed bridgework. J. Clin. Periodontol. Copenhagen, v.9, p.402-414, 1982

09. NYMAN, S.; LINDHE, J.: A longitudinal study of combined periodontal and prosthetic treatment of patients with advanced periodontal disease. J. Periodontology. v.50, p.163-169, 1979.

10. NYMAN, S.; LINDHE, J.; LUNDGRESN, D. The role of occlusion for stability of fixed bridges in patients with reduced periodontal tissue support. J. Clin. Periodontol. Copenhagen, v.2, p.53, 1975.

11. RAMFJORD, S.; ASH.M. Oclusāo. 3ed. Rio de Janeiro. Guanabara, 1987. 422p.

12. ROSENBERG, M.M. et al.: Tratamento periodontal e protético para casos avançados. Rio de Janeiro: Quintessence, 1992. $415 \mathrm{p}$.

13. SELIPSKY, H.: Osseous surgery - How much need we compromise? Dent. Clin. North Am. Philadelphia. v.20, p.79. Jan. 1976.
R. Fac. Odontol.

Porto Alegre

V. 33

N. 2 p.32-34 DEZEMBRO 